\title{
Extracellular Dopamine and Neurotensin in Rat Prefrontal Cortex in vivo: Effects of Median Forebrain Bundle Stimulation Frequency, Stimulation Pattern, and Dopamine Autoreceptors
}

\author{
Andrew J. Bean ${ }^{\mathrm{a}}$ and Robert H. Roth \\ Departments of Pharmacology and Psychiatry, Yale University School of Medicine, New Haven, Connecticut 06510
}

\begin{abstract}
In vivo microdialysis coupled with HPLC and radioimmunoassay techniques were used to analyze dopamine (DA) and neurotensin (NT) in prefrontal cortical extracellular fluid following electrical stimulation of mesocortical axons. The release (overflow into the extracellular fluid) of both DA and NT increased with increasing number of impulses and with frequency. At the lowest frequency tested $(2.5 \mathrm{~Hz})$, DA release was significantly increased, while there was no significant increase in the release of NT. As the frequency of stimulation was increased from 2.5 to $20 \mathrm{~Hz}$, the ratio of extracellular DA:NT decreased exponentially. Stimulation in a burst pattern produced greater release of both DA and NT than tonic stimulation when the number of impulses per second and the total number of impulses were held constant. Furthermore, blockade of DA autoreceptors with sulpiride stereoselectively increased the release of DA while decreasing the release of NT. These data suggest that the release of coexistent molecules (DA and NT) from mesocortical neurons can be influenced by physiological and pharmacological factors such that under certain conditions simultaneous or differential release may occur.
\end{abstract}

Dopamine (DA) and neurotensin (NT) are colocalized in a subpopulation of mesenccphalic ncurons within the ventral tegmental area (Hökfelt et al., 1984; Seroogy et al., 1988). Some of the mixed DA:NT neurons in the ventral tegmental area have been shown to project to the prefrontal cortex, a brain region that does not contain intrinsic DA or NT cells (Jennes et al., 1982; Seroogy et al., 1987, 1988; Studler et al., 1988). Using the elution restaining technique, Studler et al. (1988) have reported that all fibers stained for tyrosine hydroxylase in the deep layers of the prefrontal cortex also exhibit NT-like immunoreactivity. In addition, some DA and NT in the prefrontal cortex are costored in a reserpine-sensitive storage pool, although the majority of DA and NT appear to be stored in separate pools (Bean et al., 1989a).

Recent studies have suggested that the release of colocalized molecules can be affected by the frequency and pattern of axonal

\footnotetext{
Received Aug. 7, 1990; revised Apr. 2, 1991; accepted Apr. 3, 1991.

We thank Dr. Lothar Jennes for supplies of antiserum, Dr. R. J. Robbins and the Yale Neuroendocrine Program for use of equipment and laboratory space, and Drs. G. K. Aghajanian, C. W. Berridgc, B. S. Bunney, W. A. Clark, A. Y. Deutch, M. J. During, P. D. Shepard, and B. W. Strowbridge for helpful discussions during these studies. This work was supported in part by NIGMS Grants GM 07324, MH-14092, and The Scottish Rite Schizophrenia Research Program.

Correspondence should be addressed to Dr. Roth, Department of Pharmacology, Yale University School of Medicine, New Haven, CT 06510.

a Present address: Department of Histology and Neurobiology, Karolinska Institute, S-10401 Stockholm, Sweden.
}

Copyright $@ 1991$ Society for Neuroscience $0270-6474 / 91 / 112694-09 \$ 03.00 / 0$ stimulation such that at low frequencies the nonpeptide transmitter is released while at higher frequencies or during bursts of action potentials the peptide transmitter is preferentially released (Dutton and Dyball, 1979; Lundberg et al., 1986, 1989; Bloom et al., 1987; Bartfai et al., 1988). In this regard, mesencephalic DA neurons have been shown to fire in two modes: an "irregular" mode in which single spikes are observed with a frequency of 2-9 Hz and a "bursting" mode in which groups of action potentials (with interspike intervals corresponding to instantaneous frequencies of $10-20 \mathrm{~Hz}$ ) are separated by hundreds of milliseconds (Wang, 1981; Chiodo et al., 1984; Grace and Bunney, 1984; Shepard and German, 1988; Gariano et al., 1989).

One mechanism by which mesocortical DA neurons are known to modulate their own transmission involves the control of DA release via presynaptic DA autoreceptors (Wolf and Roth, 1987). Activation of release-modulating DA autoreceptors results in a decrease in the release of DA (Wolf and Roth, 1987). Recent studies have suggested that presynaptic receptors that regulate the release of one transmitter molecule may also regulate the release of other coexisting transmitters (Iverfelt et al., 1986; Bartfai et al., 1988).

We have previously demonstrated that electrical stimulation of mesocortical axons in vivo increases the overflow of DA and NT into the prefrontal cortical extracellular fluid (ECF; Bean et al., 1989c). In the present study, we have further characterized the stimulation-induced release of DA and NT by examining the effects of stimulation frequency, stimulation pattern, and DA autoreceptors on levels of DA and NT in the prefrontal cortical ECF.

\section{Materials and Methods}

Animals. Male Sprague-Dawley rats (225-275 gm; Camm, Wayne, NJ) were used in all experiments. Rats were housed two or three per cage and were allowed free access to food and water at all times.

In vivo microdialysis. Dialysis probes were of concentric design using a hollow dialysis membrane (5000-MW cutoff, $300-\mu \mathrm{m}$ diameter; $\mathrm{Cu}-$ prophan, Enka, Germany) sealed at one end with epoxy resin (Devcon, Danvers, MA). Two lengths of hollow fused silica fiber $(0.140-\mathrm{mm}$ o.d.; Polymicro Technologies, Inc., Phoenix, AZ) were inserted into the dialysis tubing such that one piece went to the end (inlet) and the other slopped $4 \mathrm{~mm}$ from the end (outlet). The dialysis tubing containing the fused silica was inserted through a length of 22-gauge stainless-steel tubing, which was then sealed at both ends. A small piece of 23-gauge tubing was attached to the fused silica inlet tube with epoxy so that the inlet tube could be attached to a length of PE50 tubing that was connected to a $1-\mathrm{ml}$ syringe mounted on a syringe pump (Harvard Instruments, South Natick, MA).

All rats used for dialysis experiments were anesthetized with chloral hydrate $(400 \mathrm{mg} / \mathrm{kg}$, i.p., with supplemental doses given as needed throughout the experiment; all groups of animals were anesthetized for comparable lengths of time), and dialysis probes were placed into the 
prefrontal cortex [coordinates: $\mathrm{AP}-+3.0, \mathrm{~L}=+1.8, \mathrm{~V}=-5.5$, at a $14^{\circ}$ angle according to the atlas of Paxinos and Watson (1986)]. Artificial extracellular fluid (ECF) modified after Moghaddam and Bunney (1989) [consisting of (in mM) NaCl, $143 ; \mathrm{KCl}, 3.0 ; \mathrm{CaCl}_{2}, 1.2 ; \mathrm{MgCl}_{2}, 1.0$; phosphate, 2.0; and ascorbate, $0.1, \mathrm{pH} 7.4]$ was pumped through the dialysis probe at a rate of $2.3 \mu \mathrm{l} / \mathrm{min}$. After a 120 -min period for equilibration, samples were collected every 20 min for the duration of the experiment. The samples were divided such that part was used for DA determination while the remaining sample was frozen on dry ice for subsequent NT determinations. Determination of a baseline was made by assaying samples for DA content [NT samples were assayed by radioimmunoassay (RIA) at a later time], and a stable measurement ( $\leq 20 \%$ variation for three consecutive samples) was typically obtained 60-100 min after sample collection was begun (i.e., 180-220 min following initiation of perfusion).

The traditional approach of correcting in vivo dialysis data by using in vitro ("beaker") calibration of dialysis probes is not accurate because it does not take into account the differing diffusion and transport characteristics of the substances and the probes in brain matter (Benveniste et al., 1989). Therefore, levels of DA and NT per sample were not corrected for the average in vitro probe recovery. However, estimates of the in vitro recovery for DA and NT were performed to check the transportability of the substances across the dialysis membrane. Perfusion $(2.3 \mu \mathrm{l} / \mathrm{min})$ of various concentrations $(10,100$, and $1000 \mathrm{fmol}$ in $50 \mu \mathrm{l}$ ) of DA and NT contained in glass beakers at room temperature showed that the average in vitro recovery of DA was $14.2 \pm 0.5 \%$, while the average in vitro recovery of NT was $2.0 \pm 0.1 \%$.

Radioimmunoassay of NT. The assay of NT was performed as previously described (Bean et al., 1989b). Briefly, sodium phosphate buffer ( $50 \mathrm{~mm}$, pH 7.4) containing EDTA (10 mM), bovine serum albumin $(0.1 \%)$, and sodium azide $(0.02 \%)$ was added to unknowns and standards along with NT antiserum that recognizes the $\mathrm{COOH}$ terminal of NT (Jennes et al., 1982; Bean et al., 1989b). The samples were then incubated at $4^{\circ} \mathrm{C}$ for $24 \mathrm{hr}$, at which time ${ }^{125} \mathrm{I}-\mathrm{NT}$ (Tyr ${ }^{3}-\mathrm{I}, 2000 \mathrm{Ci} / \mathrm{mmol}$; Amersham) was added, followed by an additional 24-hr incubation period at $4^{\circ} \mathrm{C}$. Bound and free ${ }^{125} \mathrm{I}-\mathrm{NT}$ were separated using a secondary antibody, and bound and free ratios were corrected for nonspecific binding, which was typically $1-2 \%$ of total binding. $T$ he $\mathrm{IC}_{50}$ for synthetic NT was $4.1 \pm 0.7 \mathrm{fmol}$, while the detection limit of the assay was 0.15 $\pm 0.026 \mathrm{fmol}$. Liquid chromatographic scparation of dialysis samples followed by radioimmunoassay revealed that our assay recognizes authentic NT from brain dialysate (Bean et al., 1989b). The stimulated release of NT has been shown to be dependent on extracellular calcium (Bean et al., 1989b,c).

Chromatography of $D A$. DA concentrations were measured as previously described (Bean et al., 1989b). In brief, dialysate was injected onto a narrow-bore $C-18$ column $(10 \mathrm{~cm} \times 2.1 \mathrm{~mm}, 3-\mu \mathrm{m}$ particle size $)$. Selective retention of DA was achieved with a mobile phase consisting of $0.05 \mathrm{~m}$ sodium phosphate buffer ( $\mathrm{pH} 5.8)$ with $0.1 \mathrm{~mm}$ EDTA, 2.2 mM sodium octyl sulfate, $5 \mathrm{~mm}$ triethylamine, and $15 \%$ methanol at a flow rate of $0.3 \mathrm{ml} / \mathrm{min}$. Electrochemical detection was accomplished using an LC-3 amperometric detector (Bioanalytical Systems, West Lafayette, IN) with a glassy carbon electrode $(+0.68 \mathrm{~V}$ vs $\mathrm{Ag} / \mathrm{AgCl}$ reference). Chromatograms were recorded on a chart recorder, and peak heights of unknowns were compared with standards for quantification.

Electrical stimulation-effects of frequency and pattern. Concentric bipolar stimulating electrodes (model SNEX-100, Rhodes Medical Instruments, Woodland Hills, CA) were placed into the median forebrain bundle [MFB; $\mathrm{AP}=-4.3, \mathrm{~L}=+1.6, \mathrm{~V}=-8.2$ (Paxinos and Watson, 1986)] of chloral hydrate-anesthetized rats immediately following placement of the dialysis probe. Initial experiments enabled determination of the optimal stimulating current and number of impulses to be used in subsequent experiments.

Frequency-response determinations were carried out using bipolar rectangular impulses (400 $\mu \mathrm{A}, 3-\mathrm{msec}$ impulse durations, $3000 \mathrm{im}-$ pulses) placed in time such that the stimulation fell in the middle of the 20-min collection period following establishment of a stable baseline of DA release.

Measurement of the effects of electrical stimulation on tissue levels of DA and NT involved placement of a stimulating electrode into the MFB of chloral hydrate-anesthetized rats followed $3 \mathrm{hr}$ later by stimulating at either 5 or $20 \mathrm{~Hz}$ for 3000 spikes. Rats were killed by decapitation immediately following stimulation, and prefrontal cortex was dissected as described previously (Bean et al., 1989a). A control group was implanted with stimulating electrodes in the MFB, and after $3 \mathrm{hr}$ rats were killed and prefrontal cortex was dissected. Sumples were stored at $-70^{\circ} \mathrm{C}$ until assayed for DA and NT as previously described (Bean et al., 1989a). Proteins were measured by the method of Lowry (Lowry et al., 1951).

The effects of impulse pattern on the release of DA and NT were examined following establishment of a stable baseline by comparing the release during 6-Hz tonic stimulation (1 impulse every $167 \mathrm{msec}$; total, 3600 spikes) with that observed following burst stimulation ( 6 impulses/ sec grouped into two 3 -impulse bursts, the first impulse separated from the second by $60 \mathrm{msec}$, and the second impulse separated from the third by $100 \mathrm{msec}$, followed by a $340-\mathrm{msec}$ delay; total, 3600 spikes). The parameters we used for burst stimulation mimicked those observed by Grace and Bunney (1984) to comprise an average burst based on their detailed analysis.

$D A$ autoreceptor antagonism. The effects of autoreceptor antagonism on the stimulated release of DA and NT were examined after a stable baseline of DA release was reached by perfusion of the $(+)$ and $(-)$ stereoisomers of the DA antagonist sulpiride $(10 \mu \mathrm{M})$ through the dialysis probe. After drug administration, a stable baseline was reached again prior to electrical stimulation at $10 \mathrm{~Hz}$ as before.

Histology. Rats were killed by decapitation and placement of the dialysis probes, and the stimulating electrodes were verified in every animal by sectioning ( $35 \mu \mathrm{m}$ in the coronal plane) and staining with neutral red.

Materials. The NT antiserum used in these studies was kindly donated by Dr. Lothar Jennes, Department of Anatomy, Wright Statc University School of Medicine, Dayton, OH. Synthetic NT was purchased from Bachem Inc. (Torrance, CA). ${ }^{125}$ I-NT was purchased from Amersham Inc. (Arlington Heights, IL). (+)- and (-)-sulpiride were purchased from Research Biochemicals Inc. (Natick, MA). All other reagents were of the highest quality obtainable.

Statistics. Dialysis experiments were analyzed by means of a repeatedmeasures ANOVA on the raw data, with overall significance further characterized using the Duncan's multiple range test. Analysis of curves was done using the nonlinear analysis module contained in the commercially available Systat software program (Systat Inc., Evanston, IL), which allows testing for fit to user-specified (linear and nonlinear) equations. Raw data derived from tissue experiments were analyzed using a one-way ANOVA with post hoc Dunnett's test. In some instances, raw data were transformed to reflect changes from an experimental baseline for presentation purposes.

\section{Results}

Histology

Figure 1 shows typical placement of the dialysis probe in the prefrontal cortex (Fig. $1 A$ ) and the stimulating electrode in the MFB (Fig. $1 B$ ). No measurable DA or NT was detected when the dialysis probe was outside of the medial-lateral limits of the deep layers of the prefrontal cortex, and probes were never found to be placed posterior to the genu of the corpus callosum. Stimulation-induced increases in extraceillular DA or NT were not observed in rats when the stimulating electrode was located outside of the MFB (data not shown).

\section{Electrical stimulation-effects of frequency}

In order to determine the optimum current to be used in stimulation studies, we tested 140-, 200-, 400-, and 800- $\mu$ A currents using 3-msec rectangular impulses at $10 \mathrm{~Hz}$ (3000 spikes) and observed significant increases above basal release (Fig. 2). All points on the DA and NT curves are significantly different from basal (DA: $140 \mu \mathrm{A}, F=7.04, p \leq 0.05 ; 200 \mu \mathrm{A}, F=20.41, p$ $\leq 0.05 ; 400 \mu \mathrm{A}, F=24.26, p \leq 0.05 ; 800 \mu \mathrm{A}, F=17.10, p \leq$ $0.05 ; \mathrm{NT}: 140 \mu \mathrm{A}, F=7.48, p \leq 0.05 ; 200 \mu \mathrm{A}, F=10.51, p$ $\leq 0.05 ; 400 \mu \mathrm{A}, F=14.37, p \leq 0.05 ; 800 \mu \mathrm{A}, F=23.12, p \leq$ $0.05)$. For the DA curve, $140 \mu \mathrm{A}$ and $200 \mu \mathrm{A}$ differ from all other points $(p \leq 0.05)$, and $400 \mu \mathrm{A}$ is not significantly different from $800 \mu \mathrm{A}(p>0.05)$. For the NT curve, $140 \mu \mathrm{A}$ does not differ significantly from $200 \mu \mathrm{A}(p>0.05)$, and $400 \mu \mathrm{A}$ does 

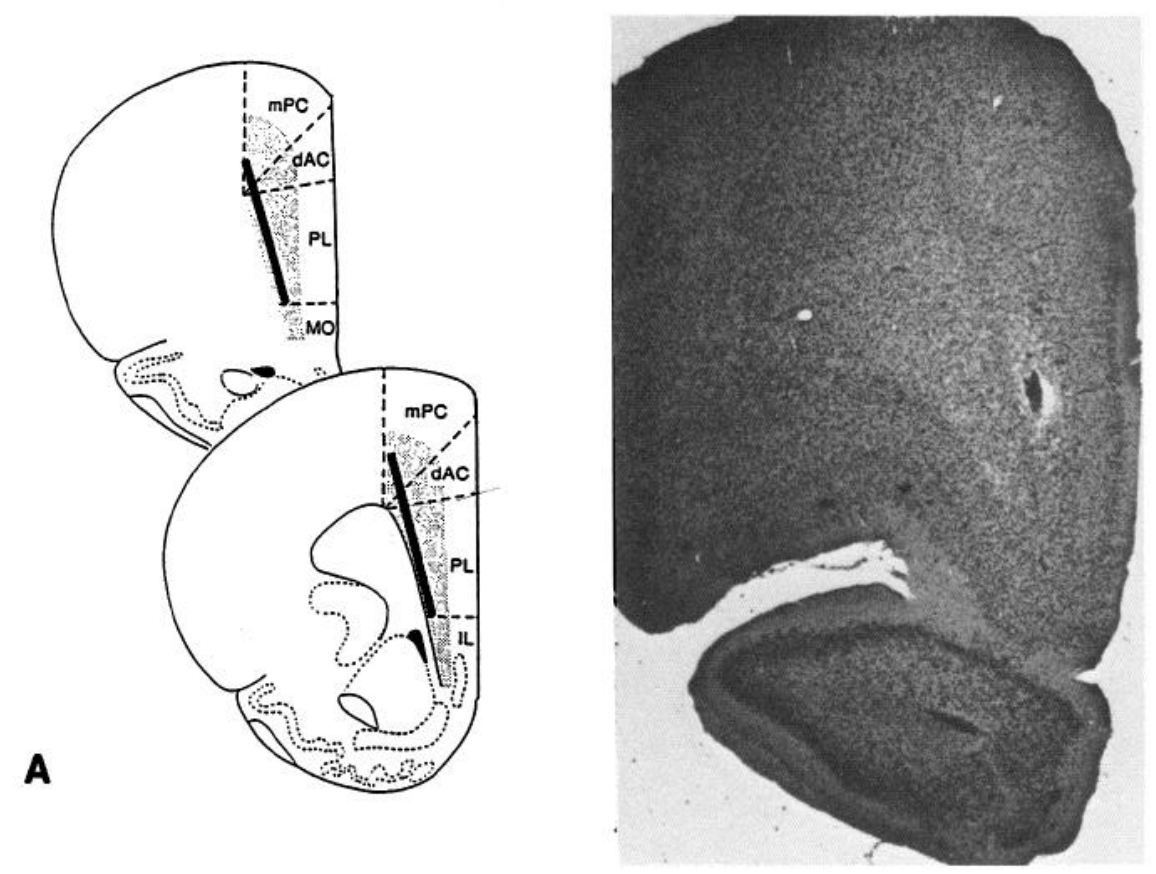

Figure 1. A, Placement of dialysis probe in the prefrontal cortex. The line drawing (modified from Paxinos and Watson, 1986) shows the cytoarchitectonic divisions of the medial prefrontal cortex, and the stippling denotes the deep layers of the medial prefrontal cortex containing the DA:NT fibers (Studler et al., 1988). The solid bar indicates the placement of the dialysis probe. The ventral extent of the dialysis probe placement can also be observed in the section (left) stained with neutral red. $m P C$, medial precentral cortex; $d A C$, dorsal anterior cingulate cortex; $P L$, prelimbic cortex; $I L$, infralimbic cortex; $M O$, medial orbital cortex. $B$, Placement of the stimulating electrode in the median forebrain bundle (*). The line drawing shows the approximate position of the stimulating electrode (solid bar). The placement of the stimulating electrode can also be observed in the section (bottom) stained with neutral red.
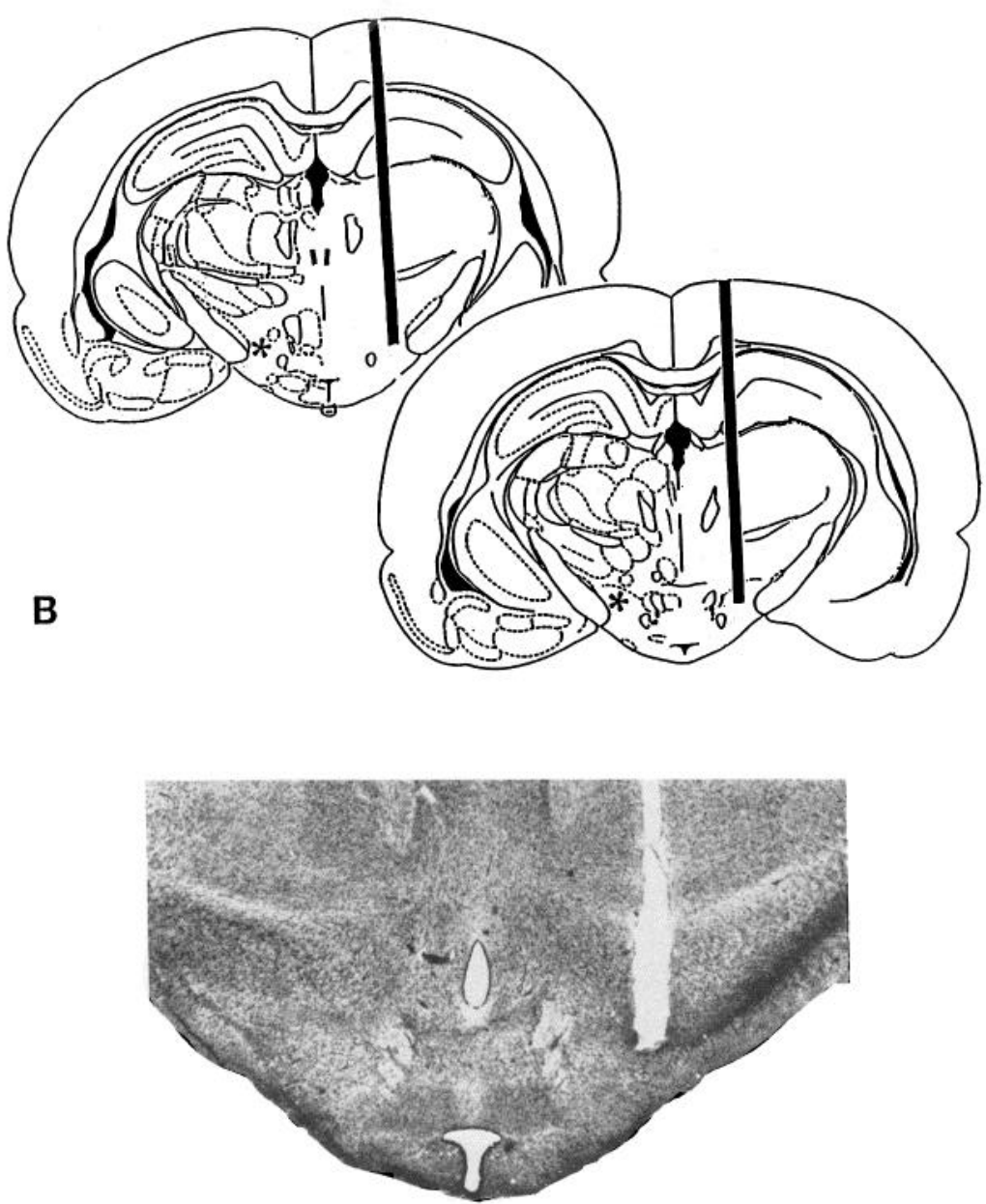


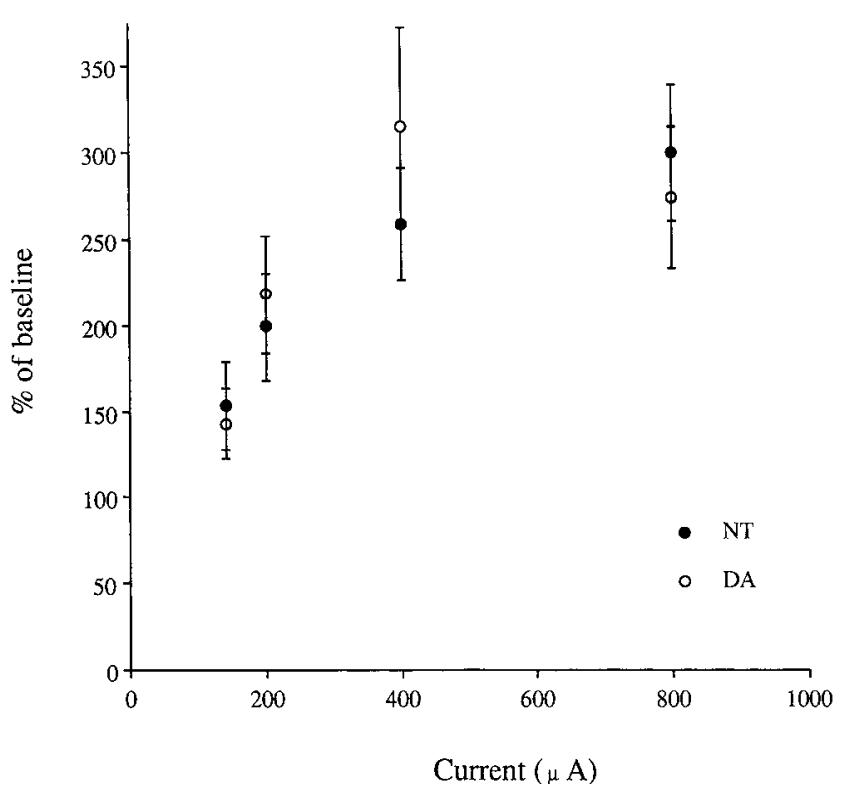

Figure 2. Effects of varying stimulation current applied to the MFB on the in vivo release of DA and NT from prefrontal cortex. A dialysis probe was placed in the prefrontal cortex, and a bipolar stimulating electrode was positioned in the MFB. After a stable baseline period, stimulation (140-800 $\mu \mathrm{A}, 3-\mathrm{msec}$ pulse duration, 3000 spikes, $10 \mathrm{~Hz})$ was begun. Data are expressed as percentage change from baseline, and each point represents the mean \pm SEM of data from six rats. Basal DA levels were $0.47 \pm 0.08 \mathrm{fmol} / \mathrm{min}$, while NT levels were $0.034 \pm 0.006$ $\mathrm{fmol} / \mathrm{min}$. All points are significantly different from basal $(p \leq 0.05)$.

not differ significantly from $800 \mu \mathrm{A}(p>0.05)$, but $140 \mu \mathrm{A}$ and $200 \mu \mathrm{A}$ are statistically different from $400 \mu \mathrm{A}$ and $800 \mu \mathrm{A}(p \leq$ 0.05 ). The current at which maximal activation of these axons occurred under these conditions was approximately $400 \mu \mathrm{A}$. Thus, we have used this current $(400 \mu \mathrm{A})$ in all subsequent studies.

The effect of the number of stimulus impulses on the release of DA and NT per min per impulse was determined (Fig. 3). By examining the release per min per impulse of DA and NT versus increasing numbers of impulses (1500-6000; using 3-msec impulses, $400 \mu \mathrm{A}, 10 \mathrm{~Hz}$ ), we have observed that the release per min per impulse for DA was significantly increased from baseline at all points $(1500: F=7.92, p \leq 0.05$; 3000: $F=$ 18.81, $p \leq 0.05 ; 3600: F=14.23, p \leq 0.05 ; 6000: F=4.07, p$ $\leq 0.05$ ), and was constant up to 3600 impulses, but was significantly reduced at 6000 impulses ( $p \leq 0.05$ vs $1500-3600$ points). The release per min per impulse for NT was significantly increased above baseline at all points (1500: $F=11.35, p \leq$ $0.05 ; 3000: F=5.92, p \leq 0.05 ; 3600: F=19.60, p \leq 0.05$; 6000: $F=21.73, p \leq 0.05$ ) and did not differ significantly throughout the range tested ( $p>0.05$; Fig. 3 ). The relationship between impulse number and DA and NT levels could be fit to linear equations (DA: $r^{2}=0.88$; NT: $r^{2}=0.96$ ). We have therefore used 3000 impulses for subsequent experiments.

Using the stimulation parameters chosen from the above studies on current and number of impulses, the effects of impulse frequency on release of DA and NT per min per impulsc wcrc examined (Fig. 4). Both DA and NT release per min per impulse increased with ascending frequency (Fig. 4). Extracellular DA was significantly different from basal at all frequencies $(2.5 \mathrm{~Hz}$ : $F=6.98, p \leq 0.05 ; 5 \mathrm{~Hz}: F=12.36, p \leq 0.05 ; 10 \mathrm{~Hz}: F=$

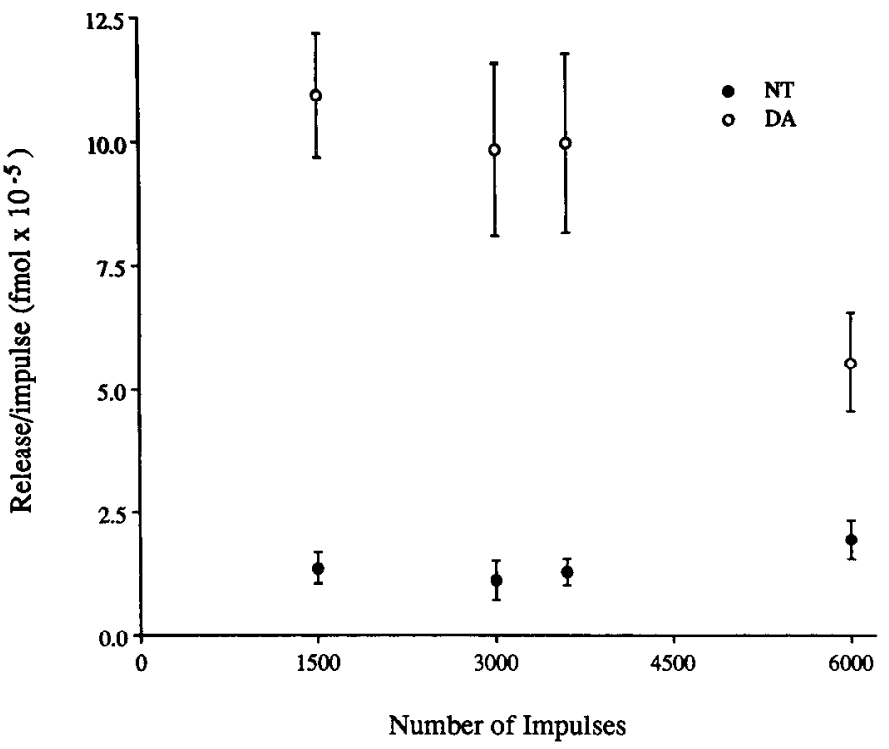

Figure 3. Effect of number of stimulation impulses on the in vivo release of DA and NT from prefrontal cortex. A dialysis probe was placed into the prefrontal cortex, and a bipolar stimulating electrode was positioned in the MFB. After a stable baseline period, stimulation (400 $\mu \mathrm{A}$, 3-msec impulse duration, 1500-6000 impulses, $10 \mathrm{~Hz}$ ) was begun. Data are expressed as increase in release (fmol) from baseline per min per impulse, and each point represents the mean \pm SEM of data from six rats. Basal DA levels were $0.37 \pm 0.05 \mathrm{fmol} / \mathrm{min}$, while NT levels were $0.024 \pm 0.006 \mathrm{fmol} / \mathrm{min}$.

19.32, $p \leq 0.05 ; 20 \mathrm{~Hz}: F=4.51, p \leq 0.05)$, and $2.5-10-\mathrm{Hz}$ points were significantly different from each other $(p \leq 0.05)$. The $20-\mathrm{Hz}$ point on the DA frequency curve was not significantly different from the $2.5-\mathrm{Hz}$ point $(p>0.05)$. Extracellular NT levels were significantly different from baseline at all points except $2.5 \mathrm{~Hz}(2.5 \mathrm{~Hz}: F=1.72, p=0.19 ; 5 \mathrm{~Hz}: F=7.73, p$ $\leq 0.05 ; 10 \mathrm{~Hz}: F=12.42, p \leq 0.05 ; 20 \mathrm{~Hz}: F=10.28, p \leq$ $0.05)$, and the $5-$ and $10-\mathrm{Hz}$ points were significantly different from each other $(p \leq 0.05)$, while the $20-\mathrm{Hz}$ point was not significantly different than either the $5-$ or $10-\mathrm{Hz}$ points $(p>$ 0.05 ). The ratio of DA:NT release decreased in a manner that could be fit by an exponential equation $\left(r^{2}=0.82\right)$ with increasing frequency (Fig. 5).

We postulated that the decrease in DA release noted at 20 $\mathrm{Hz}$ in the frequency experiment could be due to DA depletion. Therefore, we examined the effect of electrical stimulation at 5 and $20 \mathrm{~Hz}$ on the tissue content of DA and NT immediately following stimulation. Tissue levels of DA, but not NT, were significantly decreased $(26 \%, F=7.01, p \leq 0.05)$ following 20 $\mathrm{Hz}$ stimulation (Fig. 6). Tissue levels of DA and NT were not significantly different from control $(p>0.05)$ when stimulated at $5 \mathrm{~Hz}$ (Fig. 6).

\section{Electrical stimulation-effect of pattern}

The effects of stimulus pattern on DA and NT release were determined. Stimulating in bursts significantly increased the release of both DA and NT (DA: $F=10.34, p \leq 0.05$; NT: $F=$ $8.91, p \leq 0.05$ ). In fact, burst stimulation produced significantly greater increases in DA and NT release compared to tonic stimulation with the same number of impulses ( $p \leq 0.05$; Fig. 7), regardless of whether it was administered before or after tonic stimulation (data not shown). 

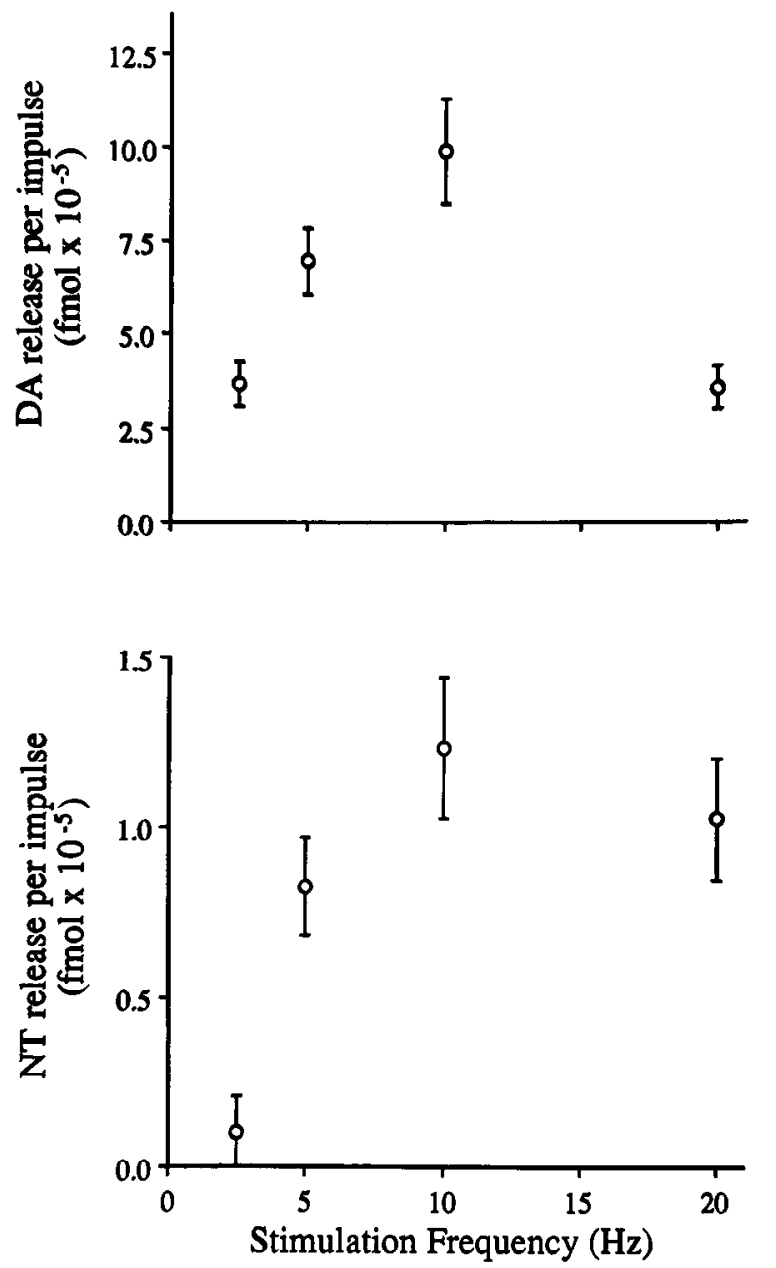

Figure 4. Effect of frequency of MFB stimulation on in vivo $\mathrm{DA}$ and NT release from prefrontal cortex. A dialysis probe was placed into the prefrontal cortex, and a bipolar stimulating electrode was positioned in the MFB. After a stable baseline period, stimulation $(400 \mu \mathrm{A}, 3-\mathrm{msec}$ impulse duration, 3000 impulses, $2.5-20 \mathrm{~Hz}$ ) was begun. Data are expressed as increase in release (fmol) from baseline per min per impulse, and each point represents the mean \pm SEM of data from six rats. Basal $\mathrm{DA}$ levels were $0.29 \pm 0.06 \mathrm{fmol} / \mathrm{min}$, while NT levels were $0.033 \pm$ $0.007 \mathrm{fmol} / \mathrm{min}$. All points except $2.5-\mathrm{Hz} \mathrm{NT}$ are significantly different from basal $(p \leq 0.05)$.

\section{Electrical stimulation-effects of DA autoreceptor blockade}

The results obtained in the frequency response experiment suggested that the frequency curve for NT reached a plateau between 10 and $20 \mathrm{~Hz}$. Since DA is depleted at $20 \mathrm{~Hz}$, decreased autoreceptor activation, and therefore a decrease in potentiation of NT release, may be expected. To determine whether DA autoreceptors may influence stimulated DA and NT release, which could account for the plateau in the NT frequency curve, we examined the effects of the two enantiomers of the DA receptor blocking agent sulpiride on electrically stimulated DA and NT release (Table 1). The active enantiomer, (-)-sulpiride, produced a significant $(94.9 \%, F=12.39, p \leq 0.05)$ increase in basal DA release and greatly facilitated the stimulated release of DA per min per impulse $\left(45 \times 10^{-5}\right.$ vs $9.9 \times 10^{-5} \mathrm{fmol}$ per $\mathrm{min} /$ pulse), whereas the inactive enantiomer, $(+)$-sulpiride, did not significantly alter basal DA release or the release of DA per min per impulse $(p>0.05$; Table 1$)$. Basal NT release was not altered significantly by either $(+)$ - or $(-)$-sulpiride. However, the stimulated release of NT per min per impulse was signifi-

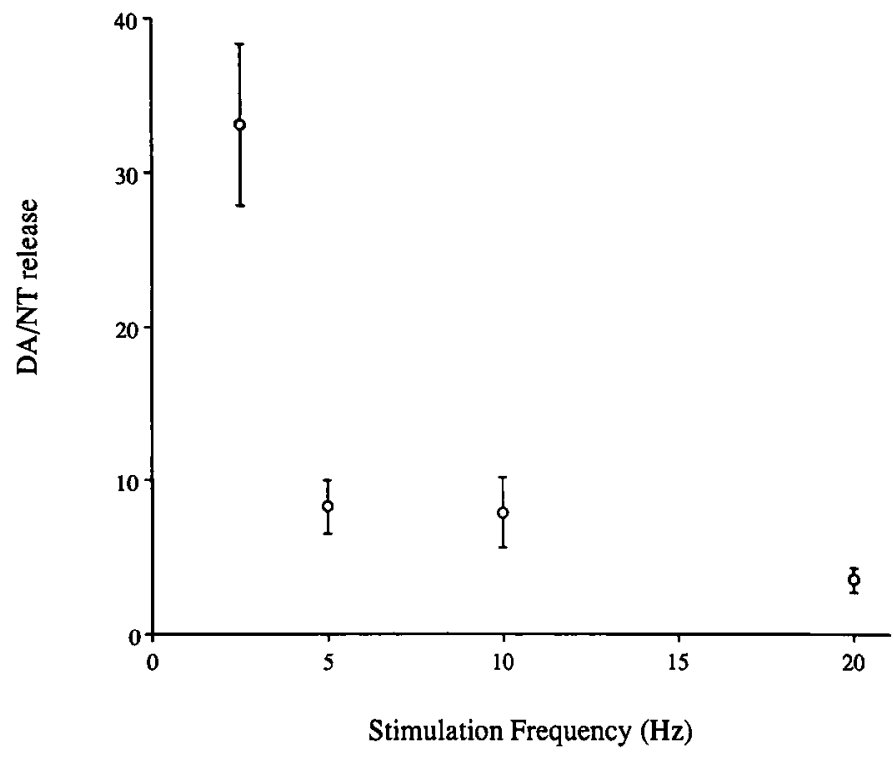

Figure 5. DA:NT release at various frequencies of stimulation: transformation of data obtained in Figure 4 to illustrate the frequency dependence of the ratio of the release of DA and NT.

cantly decreased $(F=4.14, p \leq 0.05)$ by $(-)$-sulpiride $(0.5 \times$ $10^{-5}$ vs $\left.1.1 \times 10^{-5}\right)$, while $(+)$-sulpiride did not significantly alter stimulated release (Table 1). The ratio of DA:NT release was significantly increased by (-)-sulpiride (71.4) compared to $(+)$-sulpiride $(7.0 ; p \leq 0.05$, Mann-Whitney $U$ test). DA:NT release under the identical stimulation conditions while perfusing the dialysis probe with artificial ECF was 8.0 (see Fig. 5).

\section{Discussion}

The present data suggest that the levels of DA and NT in the prefrontal cortical ECF (release) can be regulated by axonal stimulation frequency, stimulation pattern, and DA autoreceptors. Both DA and NT levels were enhanced by increasing stimulation frequency when the number of impulses was held constant. However, at the lowest frequency tested $(2.5 \mathrm{~Hz})$, only DA levels were significantly increased. Furthermore, as the frequency of stimulation increased from 2.5 to $20 \mathrm{~Hz}$, the ratio of DA release to NT release decreased exponentially. Stimulation in a burst pattern produced greater release of both DA and NT than tonic stimulation with the same number of impulses. Blockade of DA autoreceptors had opposing effects on the stimulated release of DA and NT; sulpiride treatment stereoselectively increased the release of DA while decreasing that of NT. These data suggest that in mesocortical neurons that colocalize DA and NT, DA release predominates at low firing frequencies and during DA autoreceptor blockade, whereas the release of both DA and NT are increased at higher firing frequencies and during burst stimulation.

\section{Electrical stimulation}

Mesocortical axons pass within the MFB en route to the prefrontal cortex. Previous studies employing electrical stimulation of the MFB have used a wide range of currents and impulse durations (Imperato and DiChiara, 1984; Ganon, 1988; Nicolaysen et al., 1988; May and Wightman, 1989). By varying stimulation intensity with all other parameters held constant, we observed that the maximal release of both DA and NT from the prefrontal cortex was reached at similar currents $(400 \mu \mathrm{A})$. That similar currents are required for the release of both trans- 

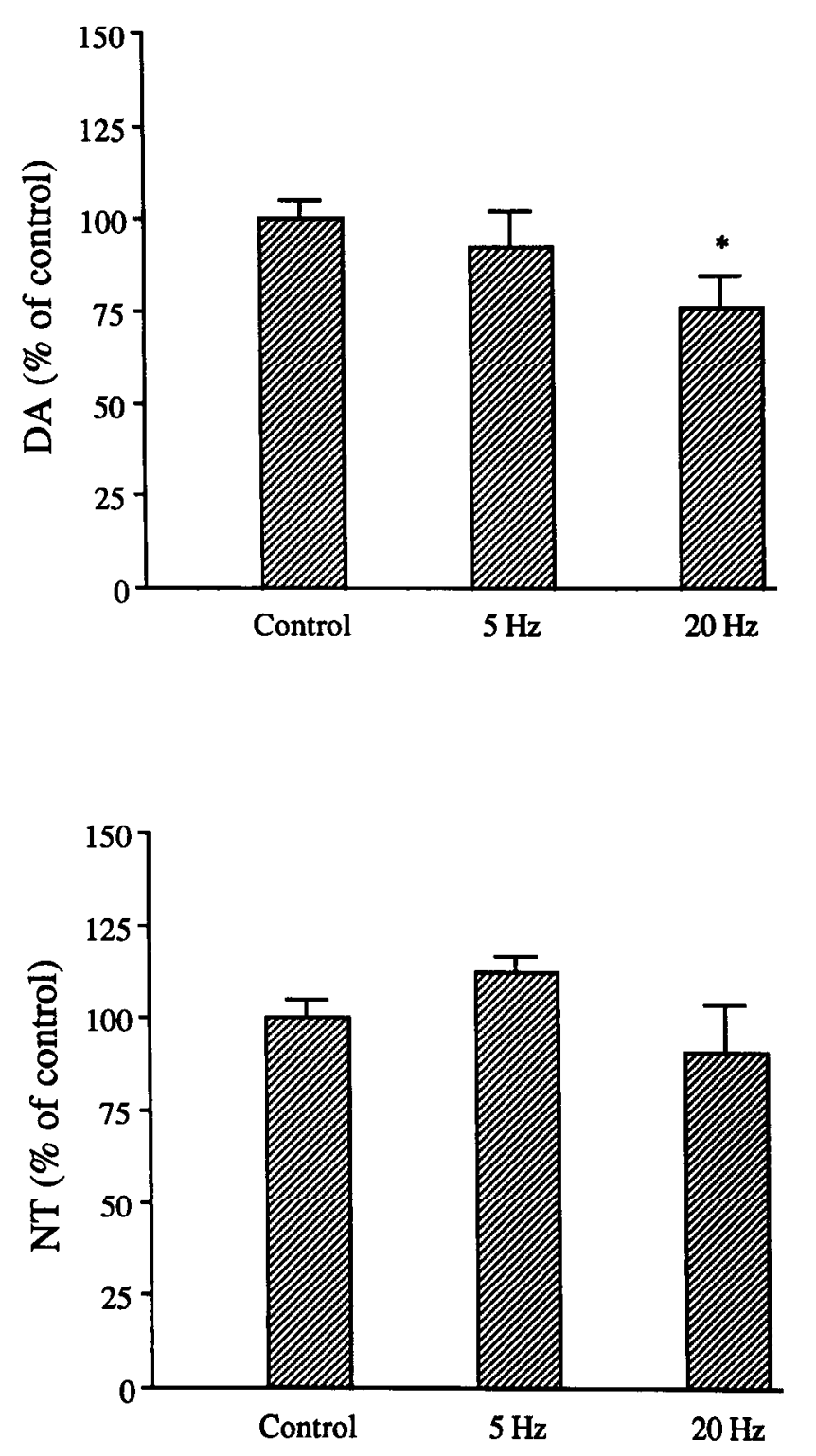

Figure 6. Effect of frequency of MFB stimulation on postmortem tissue levels of DA and NT in the prefrontal cortex. Bipolar stimulating electrodes were positioned in the MFB, and after a 2-hr period, stimulation was begun in the $5-$ and $20-\mathrm{Hz}$ groups $(400 \mu \mathrm{A}, 3-\mathrm{msec}$ impulse duration, 3000 impulses, 5 or $20 \mathrm{~Hz}$ ). Control rats received no stimulation. Following the stimulation period, the prefrontal cortex was dissected, and tissue levels were measured. Data are expressed as percent of control and represent the mean \pm SEM of six rats per group. Basal tissue levels of DA were $1.07 \pm 0.08 \mathrm{ng} / \mathrm{mg}$ protein, while NT levels were $48 \pm 2.4 \mathrm{fmol} / \mathrm{mg}$ protein. ${ }^{*}, p \leq 0.05$.

mitters is consistent with immunohistochemical studies suggesting that these transmitters are colocalized in both soma/ dendrite (Hökfelt et al., 1984) and axon-terminal (Studler et al., 1988) regions. These currents are similar to those previously reported to activate identified DA neurons antidromically (Shepard and German, 1984; Gariano et al., 1989).

Strength-duration curves suggest that unmyelinated mesocortical DA axons have relatively prolonged chronaxies (approximately $0.5 \mathrm{msec}$; Yeomans et al., 1988) as compared with myelinated axons that are also present in the MFB (approximately $50 \mu \mathrm{sec}$; Ranck, 1975). These studies suggest that no parameters for electrical stimulation of the MFB can selectively activate DA (or mixed DA/NT) fibers since long-duration pulses
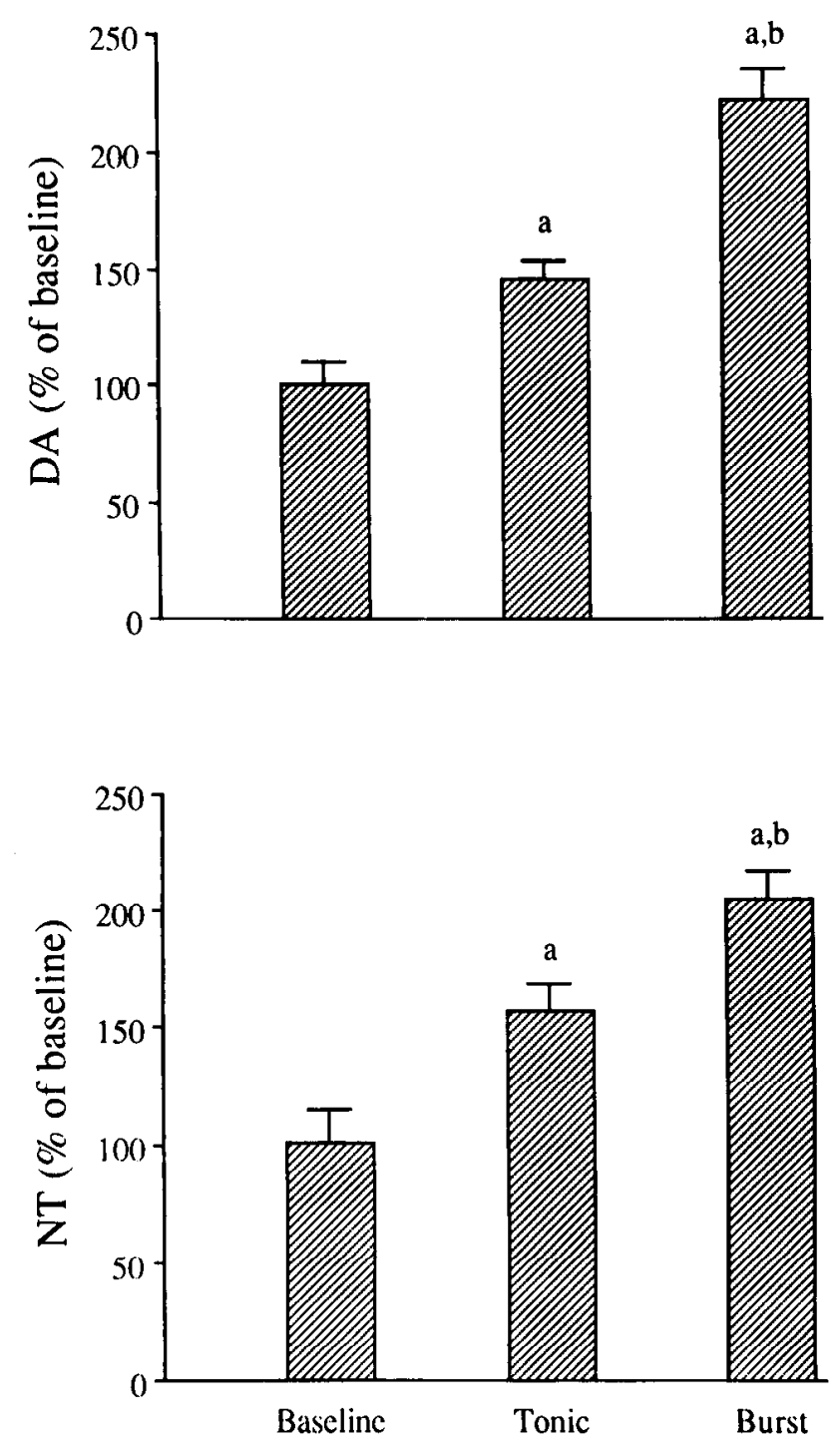

Figure 7. Effect of pattern of MFB stimulation on the release of DA and NT from prefrontal cortex. A dialysis probe was placed into the prefrontal cortex, and a bipolar stimulating electrode was positioned in the MFB. After a stable baseline period, rats received tonic stimulation $(400 \mu \mathrm{A}, 3-\mathrm{msec}$ impulse duration, 3600 impulses, $6 \mathrm{~Hz})$ followed $3 \mathrm{hr}$ later by burst stimulation ( $400 \mu \mathrm{A}, 3-\mathrm{msec}$ impulse duration, 3600 impulses, $6 \mathrm{~Hz}$; grouped into two three-impulse bursts/sec; within each burst, the first impulse was separated from the second by $60 \mathrm{msec}$ and the second impulse was separated from the third by $100 \mathrm{msec}$, followed by a 340-msec delay). Data are expressed as percent of baseline release and represent the mean \pm SEM of data from six rats. Basal DA levels were $0.45 \pm 0.07 \mathrm{fmol} / \mathrm{min}$, and NT levels were $0.030 \pm 0.006 \mathrm{fmol} /$ min. $a$, significantly different $(p \leq 0.05$ ) from baseline; $b$, significantly different from tonic stimulation at the same frequency $(p \leq 0.05)$.

and high current densities are required for activation of DA axons (Yeomans et al., 1988). We would argue, however, that the release of DA and NT in the prefrontal cortex must come mainly from the mixed mesocortical neurons since there are few, if any, intrinsic DA or NT cells in the prefrontal cortex. The findings that the currents required to maximally release DA and NT are similar and that the release of both DA and NT are linear with the number of impulses at a constant frequency (see below) support this hypothesis. We have also observed that stimulation at $10 \mathrm{~Hz}$ using short impulse durations (50 $\mu \mathrm{sec})$ does not increase prefrontal cortical release (data not shown). 
Table 1. Effect of (+)- and (-)-sulpiride on basal and stimulated (10 Hz) DA and NT release from prefrontal cortex in vivo

\begin{tabular}{|c|c|c|c|c|c|}
\hline & Basal & Drug & $\begin{array}{l}\text { Drug } \\
+10 \mathrm{~Hz}\end{array}$ & $\begin{array}{l}\text { Release per } \\
\text { min per } \\
\text { impulse } \\
\{[(\text { drug }+ \\
10 \mathrm{~Hz})- \\
\text { drug }] / 3000\}\end{array}$ & $\begin{array}{l}\text { Release per min } \\
\text { per impulse at } \\
10 \mathrm{~Hz} \text { (from Fig. } 4 \text { ) }\end{array}$ \\
\hline \multicolumn{6}{|l|}{ NT } \\
\hline (-)-Sulpiride & $0.035 \pm 0.005$ & $0.039 \pm 0.008$ & $0.054 \pm 0.008^{a}$ & $0.5 \times 10^{-5}$ & \multirow{2}{*}{$1.1 \times 10^{-5}$} \\
\hline (+)-Sulpiride & $0.026 \pm 0.003$ & $0.027 \pm 0.005$ & $0.074 \pm 0.005^{a . b}$ & $1.57 \times 10^{-5}$ & \\
\hline \multicolumn{6}{|l|}{ DA } \\
\hline (-)-Sulpiride & $0.39 \pm 0.09$ & $0.76 \pm 0.15^{c}$ & $2.12 \pm 0.37^{a, d}$ & $45 \times 10^{-5}$ & \multirow[t]{2}{*}{$9.9 \times 10^{-5}$} \\
\hline (+)-Sulpiride & $0.41 \pm 0.06$ & $0.43 \pm 0.06$ & $0.66 \pm 0.10^{a . b}$ & $7.7 \times 10^{-5}$ & \\
\hline
\end{tabular}

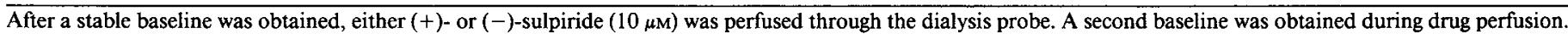

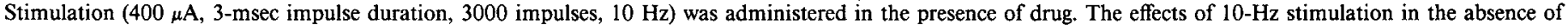
drug perfusion are taken from Figure 4 and are presented for comparison. Data are expressed as fmol $/ \mathrm{min}$ or $\mathrm{fmol} / \mathrm{min} / \mathrm{impulse}$; $n=6$ for each group.

${ }^{a}$ Significantly different from Drug or Basal $(p \leq 0.05)$.

${ }^{b}$ Significantly different from (-)-sulpiride under the same conditions $(p \leq 0.05)$.

Significantly different from Basal or stimulated under the same conditions $(p \leq 0.05)$.

${ }^{4}$ Significantly different from $(+)$-sulpiride under the same conditions $(p \leq 0.05)$.

Transmitter release evoked by stimulation of a polysynaptic pathway may appear nonlinear. However, a linear relation between the number of impulses (at a constant frequency) and transmitter release may be expected from a monosynaptic pathway. We observed linear increases in release of both DA and NT with varying number of stimuli at a constant frequency. With prolonged stimulation ( $\geq 6000$ impulses), DA release per impulse declined. The release of NT per impulse did not decline under the same conditions. These observations are consistent with results obtained on catecholamine release in numerous in vitro studies and may suggest that these conditions lead to a depletion of a "readily releasable" pool of DA (Hughes and Roth, 1974).

\section{Effects of stimulation frequency}

In our experiments, $2.5-10-\mathrm{Hz}$ stimulation increased the release of DA per min per impulse, while this response was attenuated at $20-\mathrm{Hz}$ stimulation. In a separate experiment, we observed that $20-\mathrm{Hz}$ stimulation under identical conditions produced a significant decrease in tissue content of DA. Depletion of tissue DA may correspond in part to a decrease in the pool of readily releasable DA. The release of NT per impulse increased in the frequency range of $2.5-10 \mathrm{~Hz}$, while no further increase was noted at $20 \mathrm{~Hz}$. When analyzed versus baseline, the release of NT was significantly increased at all frequencies except $2.5 \mathrm{~Hz}$. Thus, at a frequency that may approximate the basal firing frequency of at least some mesocortical DA cells in vivo $(2.5$ Hz; Wang, 1981; Shepard and German, 1984; Gariano et al., 1989; but see Chiodo et al., 1984), there is a preferential increase in release of DA from baseline. Furthermore, when the stimulation frequency was increased, the ratio of DA:NT release declined exponentially. Studies on the effect of electrical stimulation of motor neurons and sympathetic neurons that contain peptide and nonpeptide cotransmitters have also demonstrated differential release in which the release of the nonpeptide predominates at low frequencies and the peptide is released pref- erentially at higher frequencies (Iverfelt et al., 1986; Lundberg et al., 1989; Whim and Lloyd, 1989).

The effect of electrical stimulation on in vivo extracellular DA in prefrontal cortex has not been examined previously. However, in vivo methods have been utilized to examine stimulated DA release from other telencephalic regions such as the striatum and nucleus accumbens (Imperato and DiChiara, 1984; Ganon and Buda, 1985; Stamford et al., 1987; Nicolaysen et al., 1988; May and Wightman, 1989). Stimulation of the MFB in pargyline-treated, urethane-anesthetized rats has also been observed to increase DA release in olfactory tubercle as measured by in vivo voltammetry (Ganon, 1988). Stimulation-induced increases in DA release in the olfactory tubercle were noted in a frequency range of 3-14 Hz (Ganon, 1988). However, it is difficult to compare this study with ours directly because different anesthetics were employed, the DA systems in the prefrontal cortex and olfactory tubercle have different properties [e.g., the olfactory tubercle has synthesis-modulating DA autoreceptors, whereas they are nonfunctional in the prefrontal cortex (Roth, 1984)], different methods were employed (e.g., the time scales of stimulation and DA measurement are shorter for voltammetry), and different stimulation conditions were utilized (e.g.; both frequency and number of impulses were altered concurrently in the voltammetry study). These methodological differences may explain the appearance of an exponential increase in DA release noted in the voltammetry study, while we have observed DA release to be linear when increasing the number of impulses at a constant frequency, and nonlinear when increasing stimulation frequency while holding the number of impulses constant. Examination of stimulated release of ${ }^{3} \mathrm{H}-\mathrm{DA}$ in vitro from slices of prefrontal cortex has revealed that by keeping the number of impulses constant a frequency-response curve is obtained (Hoffman et al., 1988) that appears much like that observed in vivo in our present studies. In fact, these authors increased the number of impulses at the highest frequency tested $(10 \mathrm{~Hz})$ and noted a decrease in the release of ${ }^{3} \mathrm{H}-\mathrm{DA}$ per impulse (Hoffman et al., 1988). 


\section{Effects of stimulation pattern}

In addition to firing frequency, firing pattern has been shown to be an important factor in the release of chemical transmitters (Dutton and Dyball, 1979; Lundberg et al., 1986, 1989; Bloom et al., 1987; Bartfai et al., 1988). Recently, Lim et al. (1990) have recorded calcium currents and alterations in membrane capacitance (as a measure of exocytotic vesicle fusion) in single nerve terminals. These authors have shown that relative to single impulses, short "bursts" of stimuli evoke greater increases in membrane capacitance and calcium current. These results are intriguing in light of single-cell electrophysiological recordings of Grace and Bunney (1984), who have analyzed the firing patterns of mesencephalic DA neurons and have noted that these neurons can alternate between a single spike firing mode and a burst firing mode in which "average" bursts consist of three spikes (Grace and Bunney, 1984). We have examined the effect of pattern on the release of DA and NT by duplicating the bursting pattern as described by Grace and Bunney with respect to number of impulses, interspike interval, and delay time. In some systems, burst stimulation has been shown to produce a greater enhancement in the release of the peptide over the nonpeptide transmitter (Lundberg et al., 1986, 1989; Bartfai et al., 1988). However, we observed that burst stimulation increased the prefrontal cortical release of both DA and NT by approximately the same magnitude.

\section{Effects of $D A$ autoreceptors}

Mesocortical DA neurons are able to regulate their own release via activation of release-modulating nerve terminal autoreceptors (Wolf and Roth, 1987). Stimulation of these receptors by released DA reduces the subsequent release of DA from the terminal, while antagonism of DA autoreceptors can enhance the release of DA (Wolf and Roth, 1987). In some systems, presynaptic autoreceptors have been shown to regulate the release of other coexisting transmitters (Iverfelt et al., 1986; Bartfai et al., 1988). We have previously observed that DA autoreceptor stimulation reduces the basal release of DA while increasing the basal release of N'T in the prefrontal cortex (Bean et al., 1990). In the present study, sulpiride stereoselectively potentiated the stimulated release of DA while reducing the stimulation-induced increase in NT release. These data suggest that DA, by acting at its autoreceptors, could alter the frequencyrelated release of DA and NT. For example, the plateau in the frequency response for $\mathrm{NT}$ release at $20 \mathrm{~Hz}$ may be due to a lack of DA autoreceptor stimulation due to depletion of DA, which would result in decreased NT release.

Many therapeutically effective antipsychotic drugs block both pre- and postsynaptic DA receptors (Roth, 1983). The present results suggest that blockade of prefrontal cortical DA autoreceptors produces an increase in DA release and a decrease in NT release. The decrease in release of NT from mesocortical neurons following DA autoreceptor blockade may therefore be related to the therapeutic and/or side effects of antipsychotic drugs (however, see Gaspar et al., 1990).

In the present study, we have examined the effects of electrical stimulation of the MFB on the in vivo release of DA and NT from the prefrontal cortex. The data presented herein suggest that DA and NT may be differentially released based on stimulation frequency and DA autoreceptor activation within the frequency range in which these cells normally operate. The physiological mechanisms involved in frequency- and pattern-dependent release most likely involve the quantity and location of calcium entry into the terminal through different types of voltage-gated calcium channels (Miller, 1987; Boarder, 1989). According to this hypothesis, large peptide-containing vesicles require more intraterminal calcium than small non-peptidecontaining vesicles to enable exocytosis; higher calcium levels could be achieved through the opening of calcium channels with higher conductances (Miller, 1987; Lemos and Nowycky, 1989). In this regard, a recent report has described the presence of two voltage-gated calcium channels that have different conductances in single nerve terminals (Lemos and Nowycky, 1989). The mechanism(s) responsible for the modulating effects of DA autoreceptor blockade on NT release is currently under study.

\section{References}

Bartfai T, Iverfelt K, Fisone G, Serfozo P (1988) Regulation of the release of coexisting neurotransmitters. Annu Rev Pharmacol Toxicol 28:285-310

Bean AJ, Adrian TE, Modlin IM, Roth RH (1989a) Dopamine and neurotensin storage in colocalized and noncolocalized neuronal populations. J Pharmacol Exp Ther 249:681-687.

Bean AJ, During MJ, Deutch AY, Roth RH (1989b) The effects of dopamine depletion on striatal neurotensin: biochemical and immunohistochemical studies. J Neurosci 9:4430-4438.

Bean AJ, During MJ, Roth RH (1989c) Stimulation-induced release of coexistent transmitters in the prefrontal cortex: an in vivo microdialysis study of dopamine and neurotensin release. J Neurochem 53: 655-657.

Bean AJ, During MJ, Roth RH (1990) Effects of dopamine autoreceptor stimulation on the release of colocalized transmitters: in vivo release of dopamine and neurotensin from rat prefrontal cortex. Neurosci Lett 108:143-148.

Benveniste H, Hansen AJ, Ottosen NS (1989) Determination of brain interstitial concentrations by microdialysis. J Neurochem 52:17411750.

Bloom SR, Edwards AV, Garrett JR (1987) Effects of stimulating the sympathetic innervation in bursts on submandibular vascular and secretory function in cats. J Physiol (Lond) 393:91-106.

Boarder MR (1989) Presynaptic aspects of cotransmission: relationship between vesicles and neurotransmitters. J Neurochem 53:1-11.

Chiodo LA, Bannon MJ, Grace AA, Roth RH, Bunney BS (1984) Evidence for the absence of impulse regulating somadendritic and synthesis modulating autoreceptors on subpopulations of mesocortical dopamine neurons. Neuroscience 12:1-16.

Dutton A, Dyball REJ (1979) Phasic firing enhances vasopressin release from the rat neurohypophysis. J Physiol (Lond) 290:433-440.

Ganon FG (1988) Nonlinear relationship between impulse flow and dopamine released by rat midbrain dopaminergic neurons as studied by in vivo electrochemistry. Neuroscience 24:19-28.

Ganon FG, Buda M (1985) Regulation of dopamine release by impulse flow and by auto-receptors as studied by in vivo voltammetry in the rat striatum. Neuroscience 14:765-774.

Gariano RF, Tepper JM, Sawyer SF, Young SJ, Groves PM (1989) Mesocortical dopaminergic neurons. 1. Electrophysiological properties and evidence for somadendritic autoreceptors. Brain Res Bull 22: 511-516.

Gaspar P, Berger B, Febvret A (1990) Neurotensin innervation of the human cerebral cortex: lack of colocalization with catecholamines. Brain Res 530:181-195.

Grace AA, Bunney BS (1984) The control of firing pattern in nigral dopamine neurons: burst firing. J Neurosci 4:2877-2890.

Hoffmann IS, Talmaciu RK, Ferro CP, Cubeddu LX (1988) Sustained high release at rapid stimulation rates and reduced functional autoreceptors characterize prefrontal cortex dopamine terminals. J Pharmacol Exp Ther 245:761-772.

Hökfelt T, Evcritt BJ, Theodorsson-Norheim E, Goldstein M (1984) Occurrence of neurotensin-like immunoreactivity in subpopulations 
of hypothalamic, mesencephalic, and medullary catecholamine neurons. J Comp Neurol 222:543-559.

Hughes J, Roth RH (1974) Variation in noradrenalin output with changes in stimulus frequency and train length: role of different noradrenalin pools. Br J Pharmacol 51:373-381.

Imperato A, DiChiara G (1984) Trans-striatal dialysis coupled to reverse phase high performance liquid chromatography with electrochemical detection: a new method for the study of the in vivo release of endogenous dopamine and metabolites. J Neurosci 4:966-977.

Iverfelt K, Peterson LL, Brodin E, Ogern S-O, Bartfai T (1986) Serotonin type- 2 receptor mediated regulation of substance $P$ release in the ventral spinal cord and the effects of chronic antidepressant treatment. Naunyn Schmiedebergs Arch Pharmacol 333:1-6.

Iverfelt K, Serfozo P, Diaz Arnesto L, Bartfai T (1989) Differential release of coexisting neurotransmitters: frequency dependence of the efflux of substance $\mathrm{P}$, thyrotropin releasing hormone and $\left[{ }^{3} \mathrm{H}\right]$ serotonin from tissue slices of rat ventral spinal cord. Acta Physiol Scand 137: 63-71.

Jennes L, Stumpf WE, Kalivas PW (1982) Neurotensin: topographical distribution in rat brain by immunohistochemistry. J Comp Neurol 210:211-224.

Lemos JR, Nowycky MC (1989) Two types of calcium channels coexist in peptide-releasing vertebrate nerve terminals. Neuron 2:1419-1426.

Lim NF, Nowycky MC, Bookman RJ (1990) Direct measurement of exocytosis and calcium currents in single vertebrate nerve terminals. Nature 344:449-451.

Lowry OH, Rosebrough NJ, Farr AL, Randall RJ (1951) Protein measurement with the folin phenol reagent. J Biol Chem 193:265275.

Lundberg JM, Rudehill A, Sollevi A, Theodorsson-Norheim E, Hamberger B (1986) Frequency and reserpine-dependent chemical coding of sympathetic transmission: differential release of noradrenaline and neuropeptide $Y$ from pig spleen. Neurosci Lett 63:96-100.

Lundberg JM, Rudehill A, Sollevi A, Fried G, Wallin G (1989) Corelease of neuropeptide $\mathrm{Y}$ and noradrenaline from pig spleen in vivo: importance of subcellular storage, nerve impulse frequency and pattern, feedback regulation and resupply by axonal transport. Neuroscience 28:475-486.

May L, Wightman RM (1989) Effects of $D_{2}$ antagonists on frequencydependent stimulated overflow in nucleus accumbens and caudateputamen. J Neurochem 53:898-906.

Miller RJ (1987) Multiple calcium channels and neuronal function. Science 232:46-52.

Moghaddam B, Bunney BS (1989) Ionic composition of microdialysis perfusing solution alters the pharmacological responsiveness and basal outflow of striatal dopamine. J Neurochem 53:652-654.
Nicolaysen LC, Ikeda M, Justice JB Jr, Neill DB (1988) Dopamine release at behaviorally relevant parameters of nigrostriatal stimulation: effects of current and frequency. Brain Res 460:50-59.

Paxinos G, Watson C (1986) The rat brain in stereotaxic coordinates. New York: Academic.

Ranck JB Jr (1975) Which elements are excited in electrical stimulation of mammalian central nervous system: a review. Brain Res 98 : 417-440.

Roth RH (1983) Neuroleptics: functional neurochemistry. In: Neuroleptics: neurochemical, behavioral, and clinical perspectives (Coyle JT, Enna SJ, eds), pp 119-156. New York: Raven.

Roth RH (1984) CNS dopamine autoreceptors: distribution, pharmacology, and function. Ann NY Acad Sci 430:27-53.

Seroogy KB, Mehta A, Fallon IH (1987) Neurotensin and cholecystokinin coexistence within neurons of the ventral mesencephalon: projections to the forebrain. Exp Brain Res 68:277-289.

Seroogy KB, Ceccatelli S, Schalling M, Hokfelt T, Frey P, Dockray G, Buchen A, Goldstein M (1988) A subpopulation of dopamine neurons in the rat ventral mesencephalon contain both neurotensin and cholecystokinin. Brain Res 455:88-98.

Shepard PD, German DC (1984) A subpopulation of mesencephalic dopaminergic neurons possess autoreceptors. Eur $J$ Pharmacol 98: $455-456$.

Shepard PD, German DC (1988) Electrophysiological and pharmacological evidence for the existence of distinct subpopulations of nigrostriatal dopaminergic neuron in the rat. Neuroscience 27:537-546.

Stamford JA, Kruk ZL, Millar J (1987) Accommodation of rat nigrostriatal neurons to high frequency electrical stimulation of the median forebrain bundle: in vivo voltammetric data. Neurosci Lett 82:172-176.

Studler JM, Kitabgi P, Tramu G, Herve D, Glowinski J, Tassin JP (1988) Extensive colocalization of neurotensin with dopamine in rat meso-cortico-frontal dopaminergic neurons. Neuropeptides 11:95100.

Wang RY (1981) Dopaminergic neurons in the rat ventral tegmental area. I. Identification and characterization. Brain Res Rev 3:123-140.

Whim MD, Lloyd PE (1989) Frequency dependent release of peptide cotransmitters from identified cholinergic motor neurons in Aplysia. Proc Natl Acad Sci USA 86:9034-9038.

Wolf ME, Roth RH (1987) Dopamine autoreceptors. In: Structure and function of dopamine receptors-receptor biochemistry and methodology, Vol 9 (Creese I, Frasser CM, eds), pp 45-96. New York: Liss.

Yeomans JS, Maidment NT, Bunney BS (1988) Excitability properties of medial forebrain bundle axons of A9 and A10 dopamine cells. Brain Res 450:86-93. 